\title{
Development of TLC method for simultaneous estimation of novel combination of amlodipine besylate, rosuvastatin calcium, and fimasartan potassium in synthetic mixture
}

\author{
Devansh Kansara $\oplus^{1^{*}}$, Usmangani K. Chhalotiya $\oplus^{1^{*}}$ \\ Hetaben M. Kachhiya $\odot^{1}$ and Ishita Patel $\oplus^{1}$
}

${ }^{I}$ Department of Pharmaceutical Chemistry and Analysis, Indukaka Ipcowala College of Pharmacy, Beyond GIDC, P.B. No. 53, Vitthal Udyognagar- 388 121, Gujarat, India

(Received July 23, 2020; Revised September 13, 2020; Accepted September 17, 2020)

\begin{abstract}
An accurate, sensitive, robust and precise high performance thin layer liquid chromatography method was developed based on ICH Q2 (R1) guidelines for estimation of novel combination of Amlodipine besylate, Rosuvastatin calcium and Fimasartan potassium in bulk and its synthetic mixture. Pre-coated silica gel aluminum plate $60 \mathrm{~F}_{254}$ was selected as the stationary phase and $n$-hexane, $n$-butanol, methanol, and Glacial Acetic Acid (5.7:2:2.3:0.1, v/v/v/v) was selected as mobile phase. All three drugs showing appreciable absorbance at the common wavelength of $242 \mathrm{~nm}$ were selected for quantification of Amlodipine besylate, Rosuvastatin calcium, and Fimasartan potassium, respectively. The method was validated for linearity, precision, accuracy, and robustness, limit of detection and limit of quantitation as per ICH parameters. The regression coefficients $\left(\mathrm{r}^{2}\right)$ were found to be $0.9986,0.9975$ and 0.9988 for Amlodipine besylate, Rosuvastatin calcium, and Fimasartan potassium, respectively. The average percentage recovery of Amlodipine besylate, Rosuvastatin calcium and Fimasartan potassium were found to be 99.38-100-60\%, 99.75-100.63\%, 99.39$100 \%$, respectively. Thin Layer Chromatographic method has prospective qualitative as well as quantitative applications for concurrent estimation of Amlodipine besylate, Rosuvastatin calcium and Fimasartan potassium in bulk and pharmaceutical dosage form.
\end{abstract}

Keywords: HPTLC; amlodipine besylate (AML); rosuvastatin calcium (ROS); fimasartan potassium (FIM); validation. (C) 2020 ACG Publications. All rights reserved.

\section{Introduction}

According to WHO (World Health Organization), hypertension is causes death of approx. 7.5 million which is about $12.8 \%$ of total of all death per annum. There are different stages of high blood pressure like pre-hypertension, mild hypertension, moderate hypertension and severe hypertension [1].

Amlodipine besylate, Rosuvastatin calcium, and Fimasartan potassium are used to decrease high blood pressure. Chemically, Amlodipine besylate (AML) is 3-ethyl-5-methyl-[(2aminoethoxy) methyl]-4-(2-chlorophenyl)-6-methyl-1,4-dihydropyridine-3,5-dicarboxylate and having an empirical formula of $\mathrm{C}_{26} \mathrm{H}_{31} \mathrm{ClN}_{2} \mathrm{O}_{8} \mathrm{~S}$ with a molecular weight of $567.05 \mathrm{~g} / \mathrm{mol}$.

\footnotetext{
*Corresponding author: E-Mail: usmangani84@gmail.com
} 
Mechanism of action is angio-selective calcium channel blocker which results in inhibition of the contraction of cardiac muscles [2].

Chemically, Rosuvastatin calcium (ROS) is (3R, 5S, 6E)-7-(4-(4-fluorophenyl)-6-(1methylethyl)-2-(ethyl(methylsulfonyl)amino)-5-pyrimidinyl)-3,5-dihydroxy-6-heptenoic acid with an empirical formula of $\mathrm{C}_{22} \mathrm{H}_{28} \mathrm{FN}_{3} \mathrm{O}_{6} \mathrm{~S}$ and having a molecular weight $1001.14 \mathrm{~g} / \mathrm{mol}$. The mechanism of action of ROS is an inhibitor of enzyme HMG-CoA reductase which is a ratelimiting enzyme for conversation of the 3-hydroxy-3-methylglutarate to mevalonate which is the starting compound for cholesterol synthesis, ROS, along with a good and balanced diet, helps to reduce harmful LDL and helps to conserve the HDL [3].

Chemically, Fimasartan potassium (FIM) is 2-(2-butyl-4-methyl-6-oxo-1-\{[2'-(1H-1,2,3,4 tetrazol-5-yl)-[1,1'-biphenyl]-4-yl]methyl \}-1,6-dihydropyrimidin-5-yl)-N,N

dimethylethanethioamide with an empirical formula of $\mathrm{C}_{27} \mathrm{H}_{36} \mathrm{KN}_{7} \mathrm{O}_{4} \mathrm{~S}$ and having a molecular weight $593.79 \mathrm{~g} / \mathrm{mol}$. It is an angiotensin II receptor antagonist and recommended for the treatment of hypertension and cardiac failure [4]. Double combination of these drugs have been used before but current novel triple combination of AML, ROS, and FIM is under phase III clinical trials and the study has been completed in month of June 2019 as per USFDA notification [5]. The chemical structures of all three active pharmaceutical ingredients are shown in Figure 1.<smiles>CCOC(=O)C1=C(COCCN)NC(C)=C(OOC)C1c1ccccc1Cl</smiles>

(A)

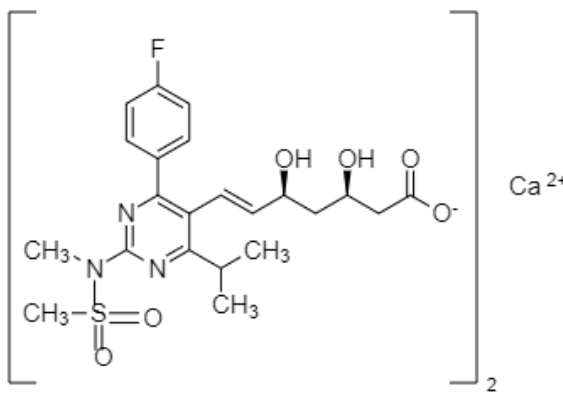

(B)

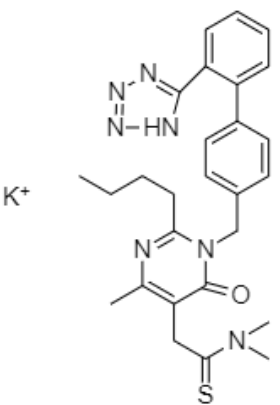

(C)

Figure 1. Structures of (A) Amlodipine besylate, (B) Rosuvastatin calcium and (C) Fimasartan potassium.

From a detailed literature review, we found that various liquid chromatographic methods [619] and HPTLC [20-22] methods have been published for the estimation of AML, ROS, and FIM in individual, combination with the any two of above active pharmaceutical ingredients and combination with other drugs. Till date no HPTLC method has been published so far for proposed triple combination. The advantages of HPTLC method is to analyze large number of samples with less amount of mobile phase, time and cost of analysis require less and also it is much faster and eco-friendly as compared to LC. The present work describes the sensitive, accurate, precise, and robust TLC method developed for the qualitative and quantitative analysis of proposed novel triple combination and method was validated as per the ICH guideline Q2(R1).

\section{Experimental}

\subsection{Chromatographic Condition}

For sample introduction, Hamilton of $100 \mu \mathrm{L}$ sample syringe was used with the help of Camag Linomat 5 (CAMAG, Switzerland) sample applicator on pre-coated silica gel aluminum plate $60 \mathrm{~F}_{254}$ was used which is having $10 \mathrm{~cm} \times 10 \mathrm{~cm}$ with $0.2 \mathrm{~mm}$ thickness, supplied by E. Merck, Germany. Camag TLC scanner was used for the densitometric scanning with HPTLC system controlled using Camag winCATS software, Version 1.4.8. For weight of all the three drugs and excipients on calibrated Sartorius CP124S (Sartorius Corporation, United States) was used. 


\subsection{Reagents and Material}

AML, ROS, and FIM are obtained from well-known pharmaceutical industry, Gujarat, India. Different solvents like HPLC grade of methanol, AR grade of $n$-Hexane and $n$-Butanol are procured from SRL Diagnostic Pvt. Ltd. Mumbai and Astron chemicals Pvt. Ltd., India. Microcrystalline cellulose and Calcium phosphate are procured from Chiti Chem Corporation Pvt. Ltd., Vadodara, India, Cross povidone, Magnesium stearate, Hydroxy propyl methyl cellulose K100M, and Cross carmellose Sodium are obtained from Chemdyes Corporation Pvt. Ltd, Vadodara, India. Whatman filter paper 42 was procured from Merck KGaA, Germany.

\subsection{Preparation of Synthetic Mixture [23]}

Synthetic mixture of the triple combination of drug with excipients was prepared for 20 tablets in the following manner. Accurately weighed excipients like Microcrystalline cellulose (4080 mg), Cross Povidone (300 mg), Calcium Phosphate (300 mg), Magnesium Stearate (111 mg), HPMC (Hydroxy propyl methyl cellulose) K100M (30 mg), Cross Carmellose Sodium (150 mg) were transferred into a mortar with pestle and mixed well. Into the above mortar pestle accurately weighed $200 \mathrm{mg}$ of Amlodipine besylate, $400 \mathrm{mg}$ of Rosuvastatin calcium, and $1200 \mathrm{mg}$ of Fimasartan potassium were added and mixed well.

From the above mixture, accurately weight equivalent to $10 \mathrm{mg}$ of AML, $20 \mathrm{mg}$ of ROS, and $60 \mathrm{mg}$ of FIM were transferred into a $100 \mathrm{~mL}$ volumetric flask containing $50.0 \mathrm{~mL}$ methanol, sonicated for 15 minutes to remove dissolved gases and improve the solubility of active pharmaceutical ingredients and the volume was made up to the mark with the same solvent. The solution was then filtered with the help of Whatman filter paper no. 42 in another $100 \mathrm{~mL}$ of volumetric flask and the volume was adjusted up to the mark with methanol to obtain the final concentration of AML $100 \mu \mathrm{g} / \mathrm{mL}, 200 \mu \mathrm{g} / \mathrm{mL}$ for ROS, and $600 \mu \mathrm{g} / \mathrm{mL}$ for FIM, respectively.

\subsection{Preparation of Stock Solution}

The concentrations of $1000 \mu \mathrm{g} / \mathrm{mL}$ for AML, $2000 \mu \mathrm{g} / \mathrm{mL}$ for ROS, and $6000 \mu \mathrm{g} / \mathrm{mL}$ for FIM were prepared individually by dissolving accurately weighed $10 \mathrm{mg}$ of AML, $20 \mathrm{mg}$ of ROS, and $60 \mathrm{mg}$ of FIM in three different $10 \mathrm{~mL}$ of volumetric flask, swirl to dissolve and volume were adjusted upto the mark with methanol for each drug. Pipetted out $1.0 \mathrm{~mL}$ of aliquot from each of above stock solutions of AML, ROS, and FIM respectively were taken into $10 \mathrm{ml}$ volumetric flask and diluted upto mark with methanol to obtain working standard solution of $100 \mu \mathrm{g} / \mathrm{mL}$ of AML, $200 \mu \mathrm{g} / \mathrm{mL}$ of ROS, and $600 \mu \mathrm{g} / \mathrm{mL}$ of FIM, respectively.

\subsection{Preparation of Stock Solution}

A narrow bands having $8 \mathrm{~mm}$ length with $9 \mathrm{~mm}$ distance between two bands of standard and sample solutions of AML, ROS, and FIM were applied on Aluminium pre-coated TLC plate.

\subsection{Mobile Phase Preparation}

Solvents mixture selected as a mobile phase, n-Hexane: n-Butanol: Methanol: Glacial Acetic Acid (5.7:2:2.3:0.1, v/v/v/v) were measured individually, mixed well and added in a twintrough glass chamber and kept for chamber saturation for 44 min with the mobile phase vapors at 25 $\pm 2{ }^{\circ} \mathrm{C}$ and managed with air conditioning system.. Ascending development method was used for development and was allowed to migrate a distance of $70 \mathrm{~mm}$. After that, TLC plates were removed and dried with a hair dryer. 


\subsection{Densitometric Analysis}

Using winCATS planar chromatography 1.4 .8 software, densitometric scanning was performed in the absorbance mode. The bands were scanned at wavelength $242 \mathrm{~nm}$ with a scanning rate of $20 \mathrm{~mm} / \mathrm{s}$. By using a linear regression equation, concentrations of the compound were chromatographed and the intensity of diffusely reflected light is determined and evaluated as peak areas against concentrations (ng/band).

\subsection{Validation}

As per International Council for Harmonization of Technical Requirements for Pharmaceuticals for Human Use guidelines Q2 (R1) for the validation parameters, validation of the developed TLC method was carried out [24].

For linearity and range, calibration curves at seven different concentrations over a range of 200-1400 ng/band for AML, 400-2800 ng/band for ROS, and 600-8400 ng/band for FIM were carried out. With the help of the winCATS 1.4.8 software, calibration was performed for five times and calibration curves were developed by plotting peak area versus concentration $(n=5)$.

LOD and LOQ is nothing but sensitivity of proposed method. By using linear regression model, these parameters were calculated from the slope and standard deviation of the intercept of calibration curves. By scanning a blank for six times, noise can be determined. LOD was calculated as 3 times of the noise level and LOQ was calculated 10 times of the noise level

The standard stock solution of $100 \mu \mathrm{g} / \mathrm{mL}$ of AML, $200 \mu \mathrm{g} / \mathrm{mL}$ of ROS, and $600 \mu \mathrm{g} / \mathrm{mL}$ of FIM were used for determination of precision. Intraday precision was calculated by analyzing solution of AML, ROS, and FIM at three different levels covering of lower, medium and higher concentration of the calibration curve three times on the same day. Interday precision was estimated by analyzing sample solution of AML, ROS, and FIM at three levels covering lower, medium and higher concentration period of three days. The peak areas were used to calculate mean percentage (\%) RSD value.

Repeatability precision was evaluated in terms of injection and scanning repeatability. The standard stock solution of $100 \mu \mathrm{g} / \mathrm{mL}$ of AML, $200 \mu \mathrm{g} / \mathrm{mL}$ of ROS, and $600 \mu \mathrm{g} / \mathrm{mL}$ of FIM were prepared and used for the repeatability study. Repeatability of the injection was studied by applying six time of middle concentration of calibration range of $800 \mathrm{ng} / \mathrm{band}$ for AML, $1600 \mathrm{ng} / \mathrm{band}$ for ROS, and $4800 \mathrm{ng} / \mathrm{band}$ for FIM. Scanning repeatability was studied by scanning the band of middle concentration of calibration range for six times.

As per ICH guidelines, the accuracy was performed by calculating \% recovery of AML, ROS and FIM by standard spiking method at three different levels 80, 100, and $120 \%$. Known amount of standard AML (480 ng/band, $600 \mathrm{ng} / \mathrm{band}$, and $720 \mathrm{ng} / \mathrm{band}$ ), standard ROS (960 ng/band, $1200 \mathrm{ng} / \mathrm{band}$, and $1440 \mathrm{ng} / \mathrm{band})$ and standard FIM (2880 ng/band, $3600 \mathrm{ng} / \mathrm{band}$, and $4320 \mathrm{ng} / \mathrm{band}$ ) were taken from standard stock solution of $100 \mu \mathrm{g} / \mathrm{mL}$ of AML, $200 \mu \mathrm{g} / \mathrm{mL}$ of ROS, and of $600 \mu \mathrm{g} / \mathrm{mL}$ of FIM. It was added to pre quantified sample and the amount of AML, ROS, and FIM were estimated by measuring the peak area by fitting these value to the straight line equation of calibration curve.

For robustness study, small deliberate changes in different chromatographic conditions like the chamber saturation time, temperatures, wavelength, and mobile phase composition of the proposed developed method were selected at concentration level of $800 \mathrm{ng} / \mathrm{band}$ for AML, 1600 $\mathrm{ng} / \mathrm{b}$ and for ROS, and $4800 \mathrm{ng} / \mathrm{band}$ for FIM, respectively. The mean $\mathrm{R}_{f}$ values and \%RSD were calculated.

The specificity of method was checked by analyzing AML, ROS, and FIM in the presence of different excipients used in synthetic mixture. By comparing $\mathrm{R}_{f}$ values and densitogram of synthetic mixture with standards, the chromatographic peaks of AML, ROS, and FIM were confirmed 


\subsection{Analysis of Synthetic Mixture}

For the preparation of synthetic mixture, AML, ROS, and FIM was taken in the ratio of 10: 20: $60 \mathrm{mg}$, respectively. Common excipients like Microcrystalline cellulose (4080 mg), Cross Povidone (300 mg), Calcium Phosphate (300 mg), Magnesium Stearate (111 mg), (HPMC) Hydroxypropyl methylcellulose K100 (30 mg), Cross Carmellose Sodium (150 mg) were weighed accurately and transfer into mortar pestle along with $200 \mathrm{mg}$ of AML, $400 \mathrm{mg}$ of ROS, and $1200 \mathrm{mg}$ of FIM which is equivalent to preparing 20 tablets. Weight accurately equivalent to $10 \mathrm{mg}$ of AML, $20 \mathrm{mg}$ of ROS, and $60 \mathrm{mg}$ of FIM transfer it a into $10 \mathrm{~mL}$ volumetric flask containing $5.0 \mathrm{~mL}$ of methanol and sonicated for $15 \mathrm{~min}$ for improving solubility of drugs and removing dissolved gases. By using Whatman filter paper No.42, the solution was filtered and collects the filtrate in another $10 \mathrm{~mL}$ volumetric flask and the residue remaining on filter paper was washed with few $\mathrm{mL}$ of methanol, both filtrate and residue washing are combined in above $10 \mathrm{~mL}$ volumetric flask and volume was adjusted up to the mark with the methanol. Form the above volumetric flask, Pipetted out $1.0 \mathrm{~mL}$ aliquot, transferred it in another $10 \mathrm{~mL}$ volumetric flask and volume was adjusted up to the mark with methanol to obtained final strength $100 \mu \mathrm{g} / \mathrm{mL}$ for AML, $200 \mu \mathrm{g} / \mathrm{mL}$ for ROS, and $600 \mu \mathrm{g} / \mathrm{mL}$ for FIM, respectively.

\section{Results and discussion}

\subsection{Optimization of Mobile Phase}

By trial and error method, the selection of the mobile phase was carried out. Different composition solvents were tried for the optimizations mobile phase like Methanol: Toluene, Methanol: Acetonitrile, Toluene: n-Butanol, $n$-Hexane: Ethyl acetate, $n$-Hexane: n-Butanol in different proportions. On the basis of above trials the mobile phase, $n$-Hexane: $n$-Butanol: Methanol: Glacial Acetic Acid (GAA) (5.7:2:2.3:0.1, v/v/v/v) showed good peak symmetry with well resolved peaks of AML, ROS and FIM, respectively (Figure S5, see supporting information). Chamber saturation time was 44 minutes and diffusion of the analyte bands occurs because of solvent migration distances greater than $70 \mathrm{~mm}$. Therefore, to validate chromatographic conditions, well resolved with good symmetry of peaks were obtained by the use of mobile phase $n$-Hexane: $n$ Butanol: Methanol: GAA (5.7:2:2.3:0.1, v/v/v/v ) with a chamber saturation time of 44 minutes at $25^{\circ} \mathrm{C}$ and solvent migration distance is $70 \mathrm{~mm}$.

\subsection{Method Validation}

Linearity relationship over the concentration range was found to be $200-1400 \mathrm{ng} / \mathrm{band}$ for AML having regression coefficient of 0.9988 , concentration ranges from 400-2800 ng/band for ROS with regression coefficient of 0.9977 and concentration ranges from 1200-8400 ng/band for FIM with regression coefficient of 0.9988 . Figure 2 shows a 3D overlay of HPTLC densitogram of the calibration concentration ranges of AML, ROS, and FIM at $242 \mathrm{~nm}$. The statistical data of calibration curve is shown in Table 1.

Table 1. Statistical data of calibration curve

\begin{tabular}{cccc}
\hline Parameter & AML & ROS & FIM \\
\hline Conc.(ng/band) & $200-1400$ & $400-2800$ & $1200-8400$ \\
Regression co-efficient $\left(\mathrm{r}^{2}\right)$ & 0.9986 & 0.9978 & 0.9988 \\
Slope of regression equation & 2.9 & 6.56 & 1.51 \\
Standard deviation of slope & 0.06 & 0.24 & 0.01 \\
Intercept of regression & 111.5 & 10260 & 3013 \\
$\quad \begin{array}{c}\text { Standard deviation of } \\
\text { intercept }\end{array}$ & 40.23 & 348.72 & 44.28 \\
$\quad \begin{array}{c}\text { Detection limit } \\
\text { (ng/band) }\end{array}$ & 42.80 & 151.75 & 283.70 \\
$\begin{array}{c}\text { Quantification limit } \\
\text { (ng/band) }\end{array}$ & 129.71 & 459.88 & 859.70 \\
\hline
\end{tabular}




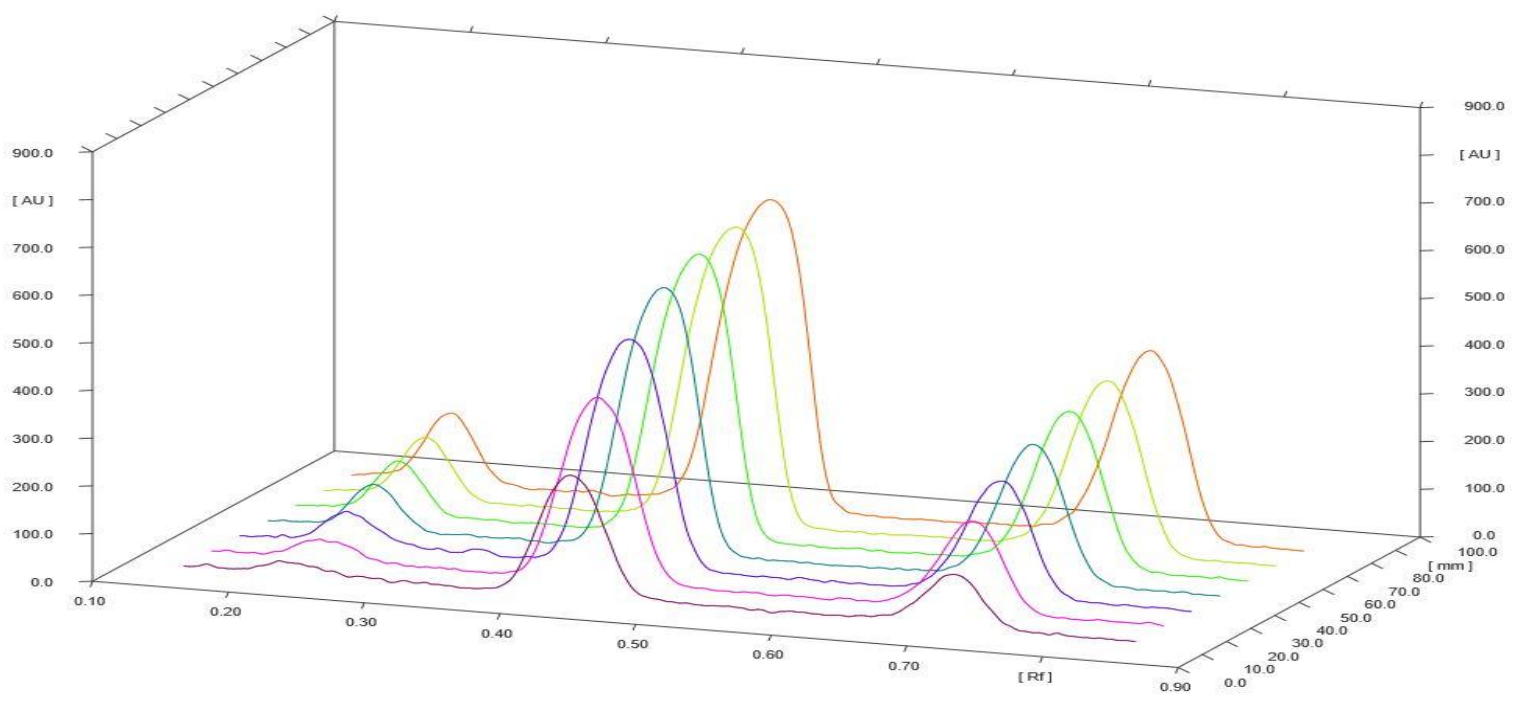

Figure 2. Three dimensional overlay densitogram of Amlodipine besylate (200-1400 ng/band), Rosuvastatin calcium (400-2800 ng/band) and Fimasartan potassium (600-8400 ng/band) using $n$-Hexane: $n$-Butanol: Methanol: Glacial Acetic Acid (5.7: 2: 2.3:0.1ml v/v/v/v) at $242 \mathrm{~nm}$.

From the Intraday and interday precision study data, \% RSD was found to be less than $3.0 \%$ which represent the proposed method is precise. From the scanning and injection repeatability data, the \%RSD was found to be less than $3.0 \%$ which represent the proposed method is repeatable.

The accuracy study of proposed method was carried out by calculating percentage (\%) recovery of drug from synthetic mixture by standard spiking method at three levels $80 \%, 100 \%$, and $120 \%$ as per ICH guidelines. For AML(480 ng/band, $600 \mathrm{ng} / \mathrm{band}$, and $720 \mathrm{ng} / \mathrm{band}$ ) were spiked, for ROS (960 ng/band, $1200 \mathrm{ng} / \mathrm{band}$, and $1440 \mathrm{ng} / \mathrm{band})$ were spiked and for FIM (2880 ng/band, $3600 \mathrm{ng} / \mathrm{band}$, and $4320 \mathrm{ng} / \mathrm{band}$ ) were spiked in pre-quantified sample solution which were prepared from synthetic mixture. From the data, the percentage (\%) recovery of $99.38-100.63 \%$ for AML, $99.75-100.63 \%$ for ROS, and $99.39-100 \%$ for FIM was obtained. The result of proposed accuracy studies is shown in Table 2 .

LOD was found to be $42.8 \mathrm{ng} / \mathrm{band}$ for AML, $151.75 \mathrm{ng} / \mathrm{band}$ for ROS and 283.7 for FIM respectively, LOQ was found to be $129.71 \mathrm{ng} / \mathrm{band}$ for AML, $460 \mathrm{ng} / \mathrm{band}$ for ROS and 860 ng/band for FIM, respectively. The peak purity from the densitogram was found to be more than 0.999 which compiles the purity of peak and peak purity spectra of calibration range is shown in Figure S6 (see supporting information).

Robustness was performed for selected chromatographic conditions and data were evaluated based on peak $\mathrm{R} f$ value of the band. The result of proposed robustness studies is shown in Table 3.

For solution stability, the solutions of sample and standard of AML, ROS and FIM were evaluated at ambient temperature $\left(25 \pm 2{ }^{\circ} \mathrm{C}\right)$.. The test was carried out over a time period of $2,4,8$ and 24 hours of time period and the percentage (\%) amount of drug was found to be $>98 \%$ by the developed HPTLC method which indicate drugs were found to be stable for cited period of time. Table 4 data are representing the summary of validation parameters of proposed method. 
Table 2. Result of proposed accuracy studies

\begin{tabular}{|c|c|c|c|c|c|c|}
\hline Drug & $\begin{array}{c}\text { \% Level of } \\
\text { spiking }\end{array}$ & $\begin{array}{l}\text { Amount of drug } \\
\text { taken from mixture } \\
\text { (ng/band) }\end{array}$ & $\begin{array}{c}\text { Amount of } \\
\text { standard drug } \\
\text { spiked (ng/band) }\end{array}$ & $\underset{(n=3)}{\operatorname{Mean} \text { Area }} \pm$ SD & $\begin{array}{l}\text { Amount of drug } \\
\text { recovered (ng/band) }\end{array}$ & Recovery \% \\
\hline \multirow[t]{4}{*}{ AML } & 0 & 600 & 0 & $1840.53 \pm 31.41$ & 596.33 & 99.38 \\
\hline & 80 & 600 & 480 & $3248.1 \pm 56.11$ & 601.82 & 100.30 \\
\hline & 100 & 600 & 600 & $3585.7 \pm 82.76$ & 598.27 & 99.71 \\
\hline & 120 & 600 & 720 & $3949.11 \pm 69.31$ & 603.61 & 100.63 \\
\hline \multirow[t]{4}{*}{ ROS } & 0 & 1200 & 0 & $18184.52 \pm 191.85$ & 1207.6 & 100.63 \\
\hline & 80 & 1200 & 960 & $24415.5 \pm 76.24$ & 1197.07 & 99.75 \\
\hline & 100 & 1200 & 1200 & $26004.67 \pm 92.57$ & 1199.23 & 99.93 \\
\hline & 120 & 1200 & 1440 & $27577.67 \pm 273.03$ & 1198.92 & 99.91 \\
\hline \multirow[t]{4}{*}{ FIM } & 0 & 3600 & 0 & $8451.67 \pm 115.51$ & 3600.23 & 100 \\
\hline & 80 & 3600 & 2880 & $12768.33 \pm 63.10$ & 3578.16 & 99.39 \\
\hline & 100 & 3600 & 3600 & $138587.7 \pm 84.1$ & 3580.05 & 99.46 \\
\hline & 120 & 3600 & 4320 & $14951.57 \pm 104.18$ & 3583.67 & 99.54 \\
\hline
\end{tabular}


Table 3. Robustness study of proposed analytical method

\begin{tabular}{|c|c|c|c|c|c|c|c|c|}
\hline Parameters & Normal Condition & $\begin{array}{l}\text { Change in } \\
\text { condition }\end{array}$ & Mean I & value $\pm S D$ & & & RSD \% & \\
\hline \multirow{3}{*}{$\begin{array}{l}\text { Change in Mobile } \\
\text { Phase Ratio }\end{array}$} & \multirow{3}{*}{$\begin{array}{c}n \text {-Hexane: } n \text {-Butanol: } \\
\text { Methanol: Glacial Acetic } \\
\text { Acid (5.7:2:2.3:0.1, } \\
\text { v/v/v/v) }\end{array}$} & & $\begin{array}{c}\text { AML } \\
\text { (800 ng/ band) }\end{array}$ & $\begin{array}{c}\text { ROS } \\
\text { (1600 ng/ } \\
\text { band) }\end{array}$ & $\begin{array}{c}\text { FIM } \\
\text { (4800 ng/ } \\
\text { band) }\end{array}$ & $\begin{array}{l}\text { AML } \\
\text { (800 ng/ } \\
\text { band) }\end{array}$ & $\begin{array}{c}\text { ROS } \\
\text { (1600 ng/ } \\
\text { band) }\end{array}$ & $\begin{array}{c}\text { FIM } \\
\text { (4800 ng/ } \\
\text { band) }\end{array}$ \\
\hline & & $\begin{array}{c}(5.8: 1.9: 2.3: 0 \\
.1, \mathrm{v} / \mathrm{v} / \mathrm{v} / \mathrm{v})\end{array}$ & $0.21 \pm 0.005$ & $0.43 \pm 0.01$ & $0.70 \pm 0.02$ & 2.7 & 2.32 & 2.94 \\
\hline & & $\begin{array}{c}(5.6: 2.1: 2.3: 0 \\
.1, \mathrm{v} / \mathrm{v} / \mathrm{v} / \mathrm{v})\end{array}$ & $0.22 \pm 0.005$ & $0.43 \pm 0.01$ & $0.70 \pm 0.01$ & 2.71 & 2.64 & 2.16 \\
\hline \multirow{3}{*}{$\begin{array}{l}\text { Chamber } \\
\text { saturation }\end{array}$} & \multirow{3}{*}{$44 \min$} & $42 \mathrm{~min}$ & $0.20 \pm 0.005$ & $0.44 \pm 0.01$ & $0.71 \pm 0.01$ & 2.79 & 2.27 & 1.40 \\
\hline & & & & & $072+001$ & & & \\
\hline & & $46 \min$ & $0.21 \pm 0.005$ & $0.44 \pm 0.005$ & & 2.64 & 1.30 & 1.38 \\
\hline \multirow{2}{*}{$\begin{array}{l}\text { Change in } \\
\text { wavelength }\end{array}$} & \multirow{2}{*}{$242 \mathrm{~nm}$} & $244 \mathrm{~nm}$ & $0.20 \pm 0.002$ & $0.43 \pm 0.003$ & $\begin{array}{l}0.71 \pm \\
0.001\end{array}$ & 2.93 & 2.36 & 2.65 \\
\hline & & $240 \mathrm{~nm}$ & $0.21 \pm$ & $\begin{array}{c}21622.79 \pm \\
515.52 \\
\end{array}$ & $\begin{array}{c}10341.25 \pm \\
289.71 \\
\end{array}$ & 1.82 & 2.38 & 2.80 \\
\hline \multirow{2}{*}{$\begin{array}{c}\text { Change in } \\
\text { temperature of } \\
\text { working area }\end{array}$} & \multirow{2}{*}{$25^{\circ} \mathrm{C}$} & $20^{\circ} \mathrm{C}$ & $0.21 \pm 0.002$ & $0.44 \pm 0.003$ & $\begin{array}{l}0.71 \pm \\
0.005\end{array}$ & 2.73 & 2.44 & 2.21 \\
\hline & & $30^{\circ} \mathrm{C}$ & $0.21 \pm 0.004$ & $0.43 \pm 0.004$ & $\begin{array}{l}0.70 \pm \\
0.005\end{array}$ & 1.8 & 2.16 & 2.70 \\
\hline
\end{tabular}


Table 4. Summary of validation parameters of proposed analytical methods

\begin{tabular}{lccc}
\hline \multicolumn{1}{c}{ Parameters } & AML & ROS & FIM \\
\hline Linearity (ng/band) & $200-1400$ & $400-2800$ & $1200-8400$ \\
Retention factor & 0.21 & 0.42 & 0.7 \\
Detection limit (ng/band) & 42.80 & 151.7 & 283.70 \\
Quantitation limit (ng/band) & 129.71 & 459.87 & 859.7 \\
Accuracy (\%) & $99.38-100.63$ & $99.75-100.63$ & $99.39-100$ \\
Precision (\%RSD) & & & \\
Intra-day (n=3) & $1.01-1.63$ & $0.72-1.88$ & $0.96-1.57$ \\
Inter-day (n=3) & $0.7-2.25$ & $2.64-2.84$ & $2.07-2.34$ \\
Specificity & Specific & Specific & Specific \\
Robustness & Robust & Robust & Robust \\
Solution stability & Stable for $24 \mathrm{~h}$ & Stable for $24 \mathrm{~h}$ & Stable for $24 \mathrm{~h}$ \\
\hline
\end{tabular}

\subsection{Analysis of synthetic mixture}

The proposed HPTLC method is successfully applied for the determination of AML, ROS, and FIM in their synthetic mixture. The percentage (\%) amount of drug for was found to be more than 98\% AML, ROS, and FIM, respectively. The chromatogram of standard and marketed formulation of AML (800 ng/band), ROS (1600 ng/band), and FIM (4800 ng/band) has been carried out. Figure S7 (see supporting information) is representing the densitogram of synthetic mixture.

\section{Conclusion}

By use of proposed HPTLC method, identification and quantification of Amlodipine besylate, Rosuvastatin calcium and Fimasartan potassium has been carried out from bulk and synthetic mixture. As per ICH guidelines, the proposed validated method is found to be selective, sensitive, accurate, precise, robust, less time consuming, cost effective and eco-friendly as compared to LC technique [21].

\section{Acknowledgements}

All authors are very thankful to Indukaka Ipcowala College of Pharmacy, New Vallabh Vidyanagar and SICART, Vallabh Vidyanagar for provided that with necessary facilities to carry out research work.

\section{Supporting Information}

Supporting information accompanies this paper on http://www.acgpubs.org/journal/ journal-of-chemical-metrology

\section{ORCID}

Devansh Kansara: 0000-0001-7377-8663

Usmangani K. Chhalotiya: 0000-0003-1183-2761

Hetaben M. Kacchiya: 0000-0003-4534-6243

Ishita Patel: 0000-0002-0021-5576

\section{References}

[1] https://www.who.int/health-topics/hypertension/. (2019).

[2] https://www.drugbank.ca/drugs/DB00381. (2019).

[3] https://www.drugbank.ca/drugs/DB01098. (2019).

[4] https://www.drugbank.ca/drugs/DB09279. (2019). 
[5] U. S. National Library of Medicine (2019). Combination of Fimsartan/Amlodipine/Rosuvastatin in Patient with Essential Hypertension and Dyslipidaemia by Boryung Pharmaceutical.2019. https://clinicaltrials.gov/ct2/show/NCT03156842.(2019).

[6] D.Tajaue, A. M.Raurale and P. D. Bharande (2012). Development and validation of a RP-HPLCPDA method for simultaneous determination of rosuvastatin calcium and amlodipine besylate in pharmaceutical dosage form, J. Chem. Pharm. Res. 4, 2789-2794.

[7] D. B. Patel (2012). Simultaneous estimation of amlodipine besylate and indapamide in a pharmaceutical formulation by a high performance liquid chromatography (RP-HPLC) method, Sci. Pharm. 80, 581-590.

[8] R. N. Shah, D. B. Gandhi and M. M. Patel (2012). RP-HPLC method for simultaneous estimation of amlodipine besylate and indapamide in tablet dosage form, Int. J. Pharm. Sci. Res. 5, 633-636.

[9] J. Prajapati (2011). Analytical method development and validation of amlodipine besylate and perindopril erbumine in combine dosage form by RP-HPLC, Int. J. Pharm. Res. 3, 801-808.

[10] M. Gumustas (2013). A validated stability-indicating RP-LC method for simultaneous determination of Amlodipine and Perindopril in tablet dosage form and their stress degradation behavior under ICH-recommended stress condition, JAOAC Int. 96, 751-757.

[11] V. B. Rajua and A. R. Rao (2011). Simultaneous estimation of perindopril and amlodipine in combined dosage form by RP-HPLC method, Int. J. Chem. Sci. 9, 1290-1298.

[12] S. S. Chaitlange, I. Mohammed and D. M. Sakarkar (2008). RP-HPLC method for simultaneous estimation of amlodipine and metoprolol in tablet formulation, Asian. J. Pharm. 12, 232-234.

[13] R. K. Barman (2007). Simultaneous high performance liquid chromatographic determination of atenolol and amlodipine in pharmaceutical dosage form, Pak. J. Pharm. Sci. 20, 274-279.

[14] K. Safeer, B. Anbarasi and N. Senthilkumar (2010). Analytical method development and validation of amlodipine and hydrochlorothiazide in combined dosage form by RP-HPLC, Int. J. Chem. Tech. Res. 4, 21-25.

[15] M. I. Beludari, K. V. Prakash and G. K. Mohan (2013). RP-HPLC method for simultaneous estimation of rosuvastatin and ezetimibe from their combination tablet dosage form, Int. J. Chem. Anal. Sci. 4, 205-209.

[16] T. G. K. Murthy and J. Geethanjali (2014). Development of a validated RP-HPLC method for simultaneous estimation of metformin hydrochloride and rosuvastatin calcium in bulk and in-house formulation, J. Chromatogr. Sep. Tech. 5, 252-259.

[17] M. Ashfaq and T. Akhtar (2014), Simultaneous estimation of rosuvastatin and amlodipine in pharmaceutical formulations using stability indicating HPLC method, Brasil. J. Pharm. Sci. 50, 629638.

[18] H. W. Moon, A. I. Moon, A. M. Yousaf and H. G. Cho (2014). Evaluation of stability and simultaneous determination of fimasartan and amlodipine by a HPLC method in combination tablets, Asian. J. Pharm. Sci. 9, 123-128.

[19] D. A. Kansara, U. K. Chhalotiya, H. M. Kachhiya, I. M. Patel and D. A. Shah (2020). Simultaneous estimation of amlodipine besylate, Rosuvastatin calcium and fimasartan potassium trihydrate combination used in the treatment of hypertension using LC method, SN Appl. Sci. 2, 948 (9 pages).

[20] B. Dhandapani, N. Anjaneyulu and Y. Venkateshwarlu (2010). HPTLC method development and validation for the simultaneous estimation of amlodipine besylate and nebivolol hydrochloride in tablet dosage form, J. Pharm. Res. 3, 332-334.

[21] S. R. Potawale (2014). HPTLC method for simultaneous determination of Rosuvastatin and Fenifibratae in bulk and pharmaceutical formulation, Int. J. Pharm. Sci. 6, 323-326.

[22] K. Patel, U. K. Chhalotiya, H. M. Kachhiya, J. Patel, D. A. Shah and D. C. Nagda (2020). Simultaneous quantification of perindopril erbumine, indapamide and amlodipine besylate in newer combination of antihypertensive drugs in pharmaceutical dosage form by thin layer Chromatography method, Sep. Sci. Plus. 3(5), 175-184.

[23] Gimsangyeob (2019) Pharmaceutical Combination Drugs by Boryung Pharmaceutical. WO2019143213A1 https://patents.google.com/patent/EP2974719A1/en?oq=amlodipine+rosuvastatin+and+fimasartan.

[24] ICH [Validation of Analytical Procedures: Methodology Q2(R1)], International Conference on Harmonization, Food and Drug Administration, USA, (1996 \& 2005).

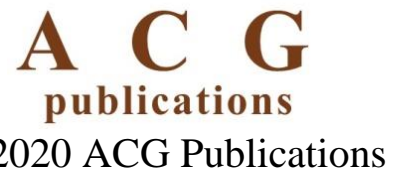

